\title{
UMA ANÁLISE DA RELAÇÃO ENTRE GOVERNANÇA CORPORATIVA E ACURÁCIA DAS PREVISÕES DOS ANALISTAS DO MERCADO BRASILEIRO
}

\section{FLÁVIA ZÓBOLI DALMÁCIO}

Doutora em Controladoria e Contabilidade pelo Departamento de Contabilidade e Atuária da Universidade de São Paulo (USP).

Professora do Departamento de Contabilidade e Atuária da Universidade de São Paulo. Avenida Professor Luciano Gualberto, 908, FEA 3, Cidade Universitária, São Paulo - SP - Brasil - CEP 05508-010 E-mail: flaviazd@usp.br

\section{ALEXSANDRO BROEDEL LOPES}

Doutor em Controladoria e Contabilidade pelo Departamento de Contabilidade e Atuária da Universidade de São Paulo (USP).

Professor do Departamento de Contabilidade e Atuária da Universidade de São Paulo. Avenida Professor Luciano Gualberto, 908, FEA 3, Cidade Universitária, São Paulo - SP - Brasil - CEP 05508-010 E-mail: broedel@usp.br

\section{AMAURY JOSÉ REZENDE}

Doutor em Controladoria e Contabilidade pelo Departamento de Contabilidade e Atuária da Universidade de São Paulo (USP).

Professor do Departamento de Contabilidade e Atuária da Universidade de São Paulo. Avenida Bandeirantes, 3.900, FEA, Monte Alegre, Ribeirão Preto - SP - Brasil - CEP 14040-905 E-mail: amauryi@usp.br

\section{ALFREDO SARLO NETO}

Doutor em Controladoria e Contabilidade pelo Departamento de Contabilidade e Atuária da Universidade de São Paulo (USP). Professor do Departamento de Contabilidade da Universidade Federal do Espírito Santo (Ufes). Avenida Fernando Ferrari, 1.358, Boa Vista, Vitória - ES - Brasil - CEP 29075-505 E-mail: sarloneto@ccje.ufes.br 


\section{RESUMO}

O objetivo deste artigo é investigar, sob a perspectiva da teoria da sinalização, a influência da adoção de práticas diferenciadas de governança corporativa sobre a acurácia das previsões do consenso (média das previsões dos lucros) dos analistas de investimento do mercado brasileiro. Investigou-se essa relação em virtude da ausência de uma teoria bem desenvolvida a respeito da natureza complexa e multidimensional da governança corporativa. A acurácia das previsões dos analistas foi mensurada a partir de metodologias propostas na literatura nacional e internacional. Como proxy para adoção de práticas diferenciadas de governança corporativa, foram utilizados os níveis diferenciados de governança corporativa da BM\&FBovespa (Nível I, Nível 2 e Novo Mercado). A amostra de trabalho da pesquisa foi composta por I05 empresas de capital aberto com ações negociadas na Bolsa de Valores de São Paulo e que possuíam cobertura regular dos analistas de mercado, durante o período de 2000 a 2008 . Foram consideradas tanto as instituições financeiras quanto as não financeiras, totalizando 2.352 observações. De acordo com os resultados encontrados, há evidências de que a governança corporativa influencia positivamente a acurácia das previsões dos analistas de investimento. Desse modo, pode-se considerar que a adoção de práticas diferenciadas de governança corporativa representa um sinal positivo, emitido pelas empresas ao mercado de capitais, capaz de influenciar a acurácia das previsões do consenso dos analistas de investimento do mercado nacional, e que esse sinal representa parâmetros na mudança da probabilidade condicional que definem as crenças, tanto dos analistas na elaboração de suas previsões e recomendações quanto dos investidores na escolha de suas aplicações. Entende-se que este trabalho contribui não apenas para a literatura a respeito de governança corporativa e previsão de analistas, mas também para o mercado de capitais brasileiro (analistas, investidores, auditores, bancos, instituições de investimento, agências de rating, fundos de pensão, órgãos reguladores, associações, bolsas de valores, próprias empresas, gestores, entre outros), ao demonstrar os benefícios diretos e indiretos da adoção de práticas diferenciadas de governança corporativa por parte das empresas brasileiras. 


\section{PALAVRAS-CHAVE}

Governança corporativa; Acurácia; Previsões; Analistas; Sinalização.

\section{INTRODUÇÃO}

Os analistas de investimentos atuam como intermediários no processo de tomada de decisão dos investidores, pois auxiliam na escolha e no gerenciamento das aplicações. Ao mesmo tempo, esses analistas podem ser considerados usuários e propagadores das informações divulgadas pelas empresas, pois coletam e consolidam tais informações, avaliam o desempenho delas e realizam previsões sobre os resultados futuros, além de recomendarem operações de compra, venda e manutenção de ações para os investidores (SCHIPPER, I99I; ABARBANELL; BUSHEE, I997; HEALY; PALEPU, 200I; MARTINEZ, 2004; BHAT et al., 2006). Consequentemente, a qualidade dos dados fornecidos pelas empresas afetará a qualidade dos prognósticos feitas pelos analistas.

Mas como verificar se as informações divulgadas são fidedignas, confiáveis, relevantes e atendem aos interesses dos analistas e investidores? A adoção de práticas diferenciadas de governança corporativa pode ser parte da resposta para a questão, pois possibilita a oportunidade, qualidade e credibilidade das informações divulgadas. De acordo com Dechow e Schrand (2004), a governança afeta positivamente a qualidade dos números contábeis reportados, e lucros de boa qualidade são persistentes e previsíveis.

Além disso, evidências encontradas na literatura nacional e internacional têm mostrado que as empresas buscam sinalizar, para o mercado, por meio da adoção de mecanismos diferenciados de governança corporativa, características como: proteção aos investidores (SHLEIFER; VISHNY, I997; LA PORTA et al., 2002; SLOAN, 200I; KLAPPER; LOVE, 2002), maior valor de mercado (BLACK, 200I; BAUER et al., 2003; GOMPERS; ISHII; METRICK, 2003; DURNEV; KIM, 2004; BROWN; CAYLOR, 2004; FARBER, 2005; LEAL; CARVALHAL-DA-SILVA, 2005; BLACK et al., 2006; LARCKER; RICHARDSON; TUNA, 2007), menor volatilidade (BROWN; CAYLOR, 2004), menor custo de capital (LANG; LUNDHOLM, I996; SHLEIFER; VISHNY, I997; BLACK, 200I; BUSHMAN; SMITH, 2003; BHOJRAJ; SENGUPTA, 2003; GOMPERS; ISHII; METRICK, 2003; LEAL; CARVALHAL-DA-SILVA, 2005; BLACK et al., 2006; ALENCAR, 2007; LOPES; WALKER, 2008), melhor desempenho operacional (JENSEN; MECKLING, I976; KLAPPER; LOVE, 2002; GOMPERS; ISHII; METRICK, 
2003; BROWN; CAYLOR, 2004; LARCKER; RICHARDSON; TUNA, 2007), menor incerteza acerca dos resultados futuros (LANG; LUNDHOLM, I996; DECHOW; SCHRAND, 2004; BHAT et al., 2006), facilidade de acesso a mercados estrangeiros (LOPES; WALKER, 2008), entre outras.

Nesse caso, dado o contexto de eficácia da governança, ela pode ser considerada como sinal e instrumento útil para seus usuários, em especial para os analistas de investimento e investidores? Esse efeito sinalizador foi investigado sob a perspectiva da teoria da sinalização. De acordo com Spence (I973), os sinais funcionam como mecanismos de discriminação, num contexto de informação assimétrica, capazes de alterar as crenças e transmitir informações a outros indivíduos. Sob essa perspectiva, buscou-se responder à seguinte questão de pesquisa:

- Qual é a relação entre a acurácia das previsões dos analistas de investimento e a adoção de práticas diferenciadas de governança corporativa pelas empresas listadas na Bolsa de Valores de São Paulo (BM\&FBovespa)?

Portanto, o objetivo deste artigo é investigar, sob a perspectiva da teoria da sinalização, a influência da adoção de práticas diferenciadas de governança corporativa sobre a acurácia das previsões do consenso de analistas de investimento do mercado brasileiro. A medida de acurácia das previsões tem o objetivo de verificar quão próxima está a previsão do analista do resultado real/efetivo da empresa. Já o consenso é a média das previsões dos lucros, para uma empresa, num determinado período. A análise de consenso é baseada "na idéia de que a melhor representação das expectativas do mercado pode ser obtida por uma medida de tendência central da distribuição das projeções dos analistas" (MARTINEZ; SALIM, 2004, p. I). Dessa forma, pretende-se verificar quão eficaz é a previsão dos analistas de investimento do mercado nacional, considerando a adoção de práticas diferenciadas de governança corporativa como sinal de credibilidade e qualidade informacional.

Entende-se que este trabalho contribui não apenas para a literatura a respeito de governança corporativa e previsão de analistas, mas também para o mercado de capitais brasileiro (analistas, investidores, auditores, bancos, instituições de investimento, agências de rating, fundos de pensão, órgãos reguladores, associações, bolsas de valores, próprias empresas, gestores, entre outros), ao demonstrar os benefícios diretos e indiretos da adoção de práticas diferenciadas de governança corporativa por parte das empresas brasileiras. Ao considerar a adoção de práticas diferenciadas de governança corporativa como sinal emitido pelas empresas, esboça-se uma estrutura conceitual, dentro da qual o poder de sinalização (conteúdo informacional) dos mecanismos e das práticas diferenciadas 
de governança corporativa é determinado como característica observável e individual de cada empresa.

\section{PLATAFORMA TEÓRICA}

\subsection{TEORIA DA SINALIZAÇÃO, GOVERNANÇA CORPORATIVA E ANALISTAS DE MERCADO}

A teoria da sinalização trata dos problemas de assimetria informacional nos mercados e procura demonstrar como essa assimetria pode ser reduzida com a indicação de mais informação. Apesar de essa teoria ter sido desenvolvida no mercado de trabalho, a sinalização é um fenômeno geral aplicável em qualquer mercado com assimetria informacional (MORRIS, I987).

De acordo com Akerlof (I970), quando existe assimetria informacional entre os agentes econômicos ${ }^{\mathrm{I}}$, pode haver o comprometimento do volume de negócios realizados no mercado, pois, nesse ambiente de incerteza, em que o comprador não pode diferenciar os produtos bons dos ruins, provavelmente não haverá negociação.

Numa situação em que uma parte da transação tem uma informação que a segunda parte não tem, esta fará o que for possível para conseguir alguma ou toda a informação relevante ${ }^{2}$ (KREPS, 2004). Por exemplo, se, num mercado, existe informação oculta, ou seja, um lado da transação não pode observar o tipo ou a qualidade dos bens ou serviços oferecidos pelo outro lado ou, até mesmo, não pode observar as ações do outro lado, então, os agentes que ofertam esses bens ou serviços desejarão investir em sinais que os diferenciem dos outros (VARIAN, 2003). A sinalização é a tentativa, por parte de certos indivíduos, de comunicar suas informações privadas de um modo crível (MILGRON; ROBERTS, I992).

A teoria da sinalização, inicialmente desenvolvida para explicar problemas de informação no mercado de trabalho (SPENCE, I973), também tem suas aplicações em áreas como: finanças (ROSS, I977; LELAND; PYLE, I977; BHATTACHARYA, I979; MYERS; MAIJLUF, I984; MILLER; ROCK, I985; JOHN; WILLIAMS, I985; HARRIS; RAVIV, I99I; KLEIN; O’BRIEN; PETERS, 2002), marketing (KIRMANI; RAO, 2000), auditoria (BAR-YOSEF; LIVNAT, I984),

"Quando os agentes envolvidos no mercado possuem informações diferentes sobre as características dos ativos em negociação" (LOPES; MARTINS, 2007, p. 3I).

2 Vale ressaltar que o valor (relevância) da informação privada depende de quão correlacionada ela está com o interesse da parte desinformada (KREPS, 2004). 
comércio internacional (BRAINARD; MARTIMORT, I996; COLLIE; HVIID, 200I; SHY, 2000), direito (FARBER, 2002), terrorismo (LAPAN; SANDLER, I993), caridade (GLAZER; KONRAD, I996), casamento (BISHOP, I984; TREBILCOCK, I999; ROWTHORN, 2002), entre outras.

O trabalho pioneiro de Spence (I973) utilizou o raciocínio desenvolvido por Jonh Hasanyi ${ }^{3}$, que propôs uma forma de inserir a assimetria de informação na teoria dos jogos. O objetivo de Spence (I973) foi delinear um aparato conceitual dentro do qual o poder de sinalização de educação, experiência de trabalho, raça, sexo e outras características observáveis pudesse ser usado para distinguir os tipos de indivíduos no mercado de trabalho. Nesse trabalho, Spence (I973) enfatizou três aspectos: I. a definição e propriedade de um equilíbrio sinalizador; 2. a interação dos sinais potenciais; e 3. a eficiência alocativa do mercado.

Spence (I973) define os sinais de mercado como sendo atividades ou atributos dos indivíduos e/ou empresas, num mercado qualquer no qual, por estruturação ou acidente, alteram as crenças e transmitem informações a outros indivíduos nesse mercado. Entretanto, segundo Spence (I973), a sinalização somente funciona se os custos de sinalização são suficientemente diferentes entre aqueles que enviam os sinais.

A teoria da sinalização de Spence (I973) enfatiza que a educação funciona como um sinalizador ou como um mecanismo de discriminação entre os tipos de trabalhadores, num contexto de informação assimétrica, no mercado de trabalho. Spence (I973) afirma que a educação e os rendimentos do empregador estão positivamente correlacionados, no entanto não porque a educação aumenta a produtividade da pessoa, mas pelo fato de que os empregadores a veem como um sinal confiável, referente às habilidades dos indivíduos. De acordo com Pindyck e Rubinfeld (2002), a educação é um forte sinal no mercado de trabalho, que pode melhorar a produtividade de um indivíduo, pois pode proporcionar mais informações, conhecimentos e habilidades (úteis no trabalho). No entanto, mesmo que a educação não melhorasse a produtividade, ela ainda seria um sinal útil, pois os indivíduos mais produtivos tendem a ter mais facilidade (inteligência, disciplina e empenho) para alcançar níveis mais elevados de educação.

De acordo com essa teoria, os sinais funcionam como mecanismos de discriminação, num contexto de informação assimétrica, capazes de alterar as crenças e transmitir informações a outros indivíduos. Ou seja, se existe assimetria da informação, indivíduos e/ou empresas podem fornecer aos interessados a informação necessária, a fim de eliminar e/ou minimizar essa assimetria. O trabalho inicial de Spence (I973) foi uma tentativa de capturar os aspectos informacionais

Prêmio Nobel de Economia, I967-1968. 
da estrutura do mercado, a fim de estudar as maneiras como os mercados (de bens duráveis, de trabalho, financeiros, de alimentos, de produtos farmacêuticos, entre outros) se adaptam à falta de informação e às consequências dessas lacunas informacionais para o desempenho desses mercados.

Sob a ótica da teoria da sinalização, o que se pretende com este artigo é demonstrar que as empresas, com o intuito de atrair novos investidores e captar recursos, sinalizam, para o mercado (para analistas e investidores), por meio de seus mecanismos e práticas diferenciadas de governança corporativa, que elas podem oferecer retornos e representar boas oportunidades de investimento, além de comunicar e assegurar aos interessados sua qualidade e credibilidade informacional. As "boas empresas" (que adotam práticas diferenciadas de governança) podem oferecer tal garantia, enquanto as "empresas ruins" não podem. Ao adotarem práticas diferenciadas de governança corporativa, as empresas podem se distinguir umas das outras no mercado de capitais e possibilitar que os investimentos aconteçam (adaptado do exemplo de mercado de carros de Akerlof (I970) $)^{4}$.

De acordo com Shleifer e Vishny (1997, p. 738), "os mecanismos de governança corporativa são as instituições econômicas e legais que podem ser alteradas, por meio do processo político, às vezes, para melhor”. Essa afirmativa é consistente com a ideia de que a governança corporativa pode ser um sinal no mercado de capitais. Dessa forma, as empresas modificam ou aperfeiçoam os mecanismos e as práticas de governança e os tornam visíveis, com o objetivo de comunicar algo à outra parte (analistas de mercado e/ou investidores).

Nesse contexto, os mecanismos e as práticas diferenciados de governança corporativa, de acordo com a teoria da sinalização, representam sinais da empresa que são comunicados ao mercado, podendo alterar a distribuição de probabilidade dos analistas e/ou dos investidores. É certo que, para emitir esses sinais ao mercado, a empresa incorre em custos de sinalização, pois adotar mecanismos e práticas diferenciadas de governança corporativa custa caro. No entanto, existe a expectativa de que os benefícios (atrair novos investidores), com a emissão dos sinais, sejam superiores aos gastos incorridos.

Lopes (2008) afirma que as empresas optarão por adotar arranjos de governança superiores quando os benefícios (acesso a fontes externas de capital para financiar oportunidades de crescimento) forem maiores que os custos. No caso deste artigo, sinalização, portanto, é toda ação praticada por uma parte informada (empresa) para revelar à parte desinformada (analistas e investidores) informações particulares.

4 Em “The market for lemons': qualitative uncertainly and the market mechanism”, Akerlof (I970) se refere ao mercado de carros usados, assumindo que existem dois tipos de carros: os bons e os ruins. 
No mercado de capitais, a sinalização pode representar um elemento importante, uma vez que as empresas tendem a sinalizar para o mercado (analistas de investimento, investidores, credores, entre outros) informações que propiciem aos demandantes desses sinais uma capacidade de diferenciação, para auxiliar nas decisões de investimento sob condições (ambiente) de incerteza.

Além disso, nesse contexto de incerteza, é possível inferir que, na relação de emissão de sinais entre empresa e investidores, estes possam ter dificuldades de interpretação de todos os sinais emitidos, fato que determina a presença e participação dos analistas de investimento do mercado. Essa relação pode ser observada na Figura I e tem como finalidade discutir a presença de intermediários no processo de sinalização das empresas, fato não previsto no modelo original de Spence (I973).

\section{FigURA I}

SINALIZAÇÃO NO MERCADO DE CAPITAIS

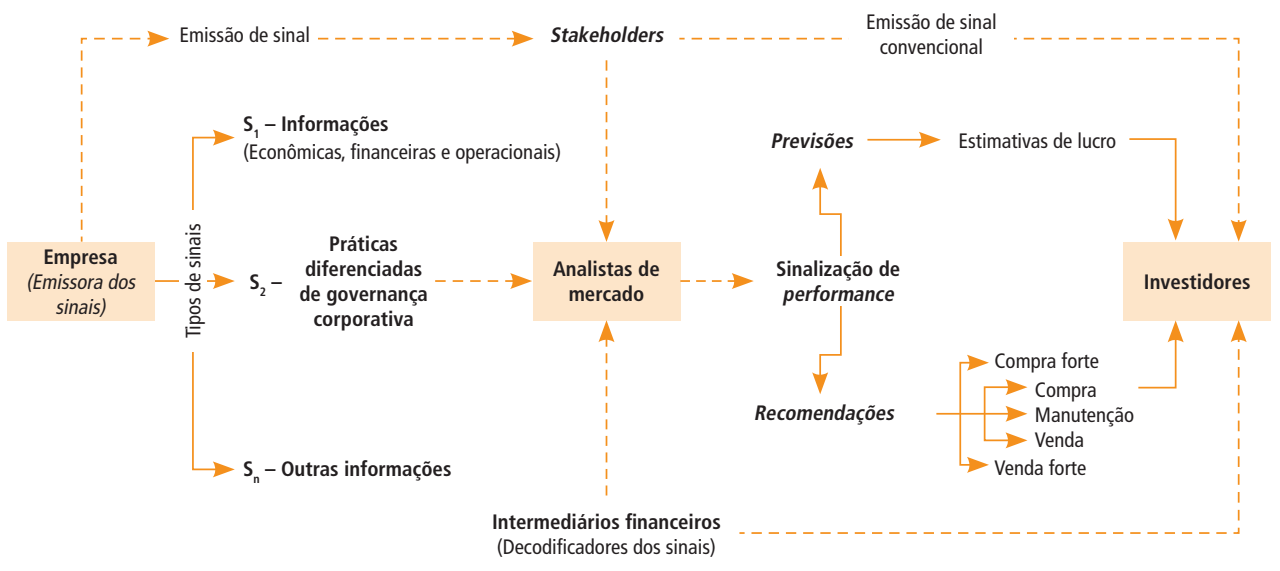

Fonte: Elaborada pelos autores.

Os analistas de mercado, nesse contexto, têm papel importante devido à sua capacidade de captar e interpretar tanto os sinais quanto os índices (sinais convencionais) e modificar a distribuição de probabilidade dos investidores, em relação às suas escolhas de investimentos (HEALY; PALEPU, 200I; MARTINEZ, 2004; YU, 2005).

Diante do fato de que os investidores não têm muita certeza da capacidade de geração de retornos dos investimentos (realizados ou a realizar), pois nem todas as informações estão disponíveis, antes da sua aplicação, os investidores tendem a recorrer às previsões e recomendações dos analistas de investimento do 
mercado, como forma de diminuir a assimetria informacional existente. Entretanto, é necessário um tempo para que ocorra o aprendizado 5 e para que novos investimentos possam ser realizados.

Algum tempo depois de fazer um investimento, o investidor irá perceber a qualidade das previsões e recomendações dos analistas, bem como a capacidade produtiva da empresa em relação aos retornos esperados. Com base em experiências anteriores, os analistas terão condições de avaliar a capacidade informacional da empresa, dadas as várias combinações de sinais e índices emitidos ao mercado. A qualquer tempo, quando confrontado com outras possibilidades de investimentos (outras empresas), com certos atributos observáveis, a avaliação subjetiva do investidor em relação à situação de incerteza, com a qual ele foi confrontado, é definida pelas distribuições de probabilidade condicional sobre a produtividade obtida, fornecendo novos dados no processo de escolha de investimentos.

Mesmo diante da interpretação dos sinais feita pelos analistas de investimento do mercado, é necessário um tempo de maturação que permita a análise e a verificação da eficácia dos sinais emitidos pelas empresas. Assim, os investidores podem medir o êxito das suas escolhas pela realização ou não dos resultados estimados pelos analistas, ao longo do período. Spence (I973) destaca o fato de que, como essas capacidades não são conhecidas previamente, a decisão é tomada sob condições de incerteza.

À luz dos pressupostos da abordagem teórica de Spence (I973), tendo em vista que o investidor não pode observar o produto marginal antes da realização do investimento, ele tende a recorrer aos analistas de investimento do mercado, considerando assim o fundamento para a avaliação da sua escolha (HEALY; PALEPU, 200I; MARTINEZ, 2004; YU, 2005). A avaliação das características observáveis e individuais das empresas feita pelos analistas é que determinará, ou não, a aquisição do investimento.

Esse processo de sinalização, segundo Spence (I973), é endógeno ao mercado, pois os analistas e investidores solicitam às empresas que transmitam informações sobre o seu desempenho atual e futuro. Esses sinais e índices emitidos representam um conjunto de elementos que têm como objetivo diminuir a assimetria informacional e a incerteza implícita à decisão de investimento e aos retornos desejados, que se constituem na distribuição de recursos e na opção de investimentos disponíveis no mercado (oferta e demanda).

De acordo com Spence (I973), a mudança das distribuições ocorre quando novos dados do mercado são recebidos e as probabilidades condicionais são revisadas ou atualizadas. Contratar no mercado deve ser considerado como amostra, e revisar as probabilidades condicionais, como uma passagem do prévio para o posterior. Todo o processo deve ser autoaprendido. 


\subsection{PESQUISAS ANTERIORES}

Na revisão de literatura realizada a respeito da associação entre governança corporativa e previsão dos analistas de mercado, destacam-se os trabalhos de Chiang e Chia (2005), Bhat et al. (2006) e Byard, Li e Weintrop (2006).

Chiang e Chia (2005) investigaram, em 225 empresas de alta tecnologia taiwanesas, durante o período de 2000 a 2002 , se mais transparência corporativa conduz a previsões mais acuradas. Os resultados revelaram que, quando a empresa evidencia mais informação sobre transparência financeira, o viés da previsão torna-se menor e, certamente, a acurácia será maior.

Bhat et al. (2006) investigaram como as diferenças na transparência da governança corporativa de 2I países afetam a acurácia da previsão dos analistas para as firmas desses países. Esses autores examinaram se os analistas de mercado utilizam os disclosures relacionados à governança corporativa na formulação das previsões de lucros e se a acurácia dessas previsões aumenta com tais disclosures. De acordo com os resultados, a dimensão da transparência da governança corporativa está, positiva e significativamente, correlacionada com a acurácia da previsão dos analistas.

Byard, Li e Weintrop (2006) examinaram a associação entre governança corporativa e qualidade da informação disponível para os analistas financeiros. Segundo os autores, a qualidade da governança corporativa está associada a um aumento na qualidade total da informação possuída por esses críticos, considerados usuários fundamentais dos disclosures financeiros fornecidos pelas empresas. Os resultados indicaram que a qualidade da informação dos analistas sobre os lucros futuros aumenta com a qualidade da governança corporativa. Os autores encontraram que os analistas acompanham empresas com melhor governança, pois, dessa maneira, possuem melhor informação sobre os lucros futuros dessas companhias.

\section{METODOLOGIA}

Por meio de investigações empírico-analíticas, buscou-se analisar o relacionamento entre as práticas diferenciadas de governança corporativa e a acurácia das previsões dos analistas de investimento do mercado brasileiro.

\subsection{AMOSTRA E DEFINIÇÃO DAS VARIÁVEIS}

A amostra de trabalho consiste num conjunto de dados em painel não balanceado e foi composta por to5 empresas de capital aberto com ações negociadas 
na BM\&FBovespa que possuíam cobertura regular dos analistas de mercado. Foram consideradas tanto as instituições financeiras quanto as não financeiras, a partir do universo das empresas de capital aberto com ações negociadas na BM\&FBovespa, no período de 2000 a 2008 , totalizando 2.352 observações $^{6}$.

Optou-se por investigar as empresas participantes do mercado de capitais brasileiro, considerando que as informações sobre as empresas, disponíveis aos analistas de mercado, dependem do ambiente institucional e do mercado de capitais, como estrutura legal/judicial, regulamentação contábil, estrutura acionária, prestígio e importância da profissão contábil, grau de influência da legislação tributária, fontes de financiamentos (LA PORTA et al., I998, I999; ALI; HWANG, 2000; BALL et al., 2000; BUSHMAN; SMITH, 200I; LOPES, 200I; BUSHMAN et al., 2004; GILLAN, 2006). Além disso, o mercado de capitais brasileiro tem uma particularidade no que se refere à segmentação de níveis de governança corporativa (Nível I, Nível 2 e Novo Mercado da BM\&FBovespa).

Dessa forma, a qualidade da governança corporativa, apresentada pelas empresas listadas na BM\&FBovespa, representa uma opção, entre os diversos mecanismos de governança existentes, que as diferencia entre si. Apesar da dificuldade que as companhias têm em otimizar, todo o tempo, suas estruturas de governança corporativa (LARCKER; RICHARDSON; TUNA, 2007), estas são, em parte, determinadas pelas características da empresa (BYARD; LI; WEINTROP, 2006).

\subsubsection{Variáveis dependentes}

- Acurácia da previsão do consenso dos analistas (APCA_N): medida derivada da metodologia utilizada por Martinez e Salim (2004) e Martinez (2004). Primeiro, de acordo com Martinez e Salim (2004) e Martinez (2004), calculou-se a diferença entre o resultado real (lucro efetivo) e o resultado projetado (lucro estimado) pelos analistas, dividido pelo valor absoluto (módulo) do resultado efetivo do período. Assim como Martinez e Salim (2004) e Martinez (2004), optou-se pela média, e não pela mediana do consenso dos analistas, pois a média "reflete com mais precisão a magnitude das estimativas e não, apenas, o número destas” (MARTINEZ; SALIM, 2004, p. 6).

Em cada observação, considera-se a previsão do analista i para a empresa j no ano t. Vale ressaltar que o número de analistas que acompanharam a empresa em cada ano é variável. Essas observações referem-se às previsões dos analistas de investimento (lucro por ação previsto), disponíveis e coletadas no banco de dados do Sistema Thomson ONE Analytics ${ }^{\circledR}$, para cada uma das empresas da amostra, num determinado período. 


$$
\text { Err Prev }=\frac{L P A_{\text {real }}-L P A_{\text {prev }}}{\left|L P A_{\text {real }}\right|}
$$

Em que: $L P A_{\text {real }}=$ lucro por ação efetivo do período; $L P A_{\text {prev }}=$ lucro por ação apurado, a partir do consenso dos analistas (média); e $\left|L P A_{\text {real }}\right|=$ valor absoluto (módulo) do lucro por ação efetivo. Em seguida, de acordo com Martinez e Salim (2004) e Martinez (2004), calculou-se a média dos erros de previsão (MEP), a fim de verificar a existência de um viés nas previsões e a média dos erros de previsão absolutos (MEPA), visando estimar a acurácia dessas previsões. Quanto mais distante de zero for o valor dessa variável, maior será o montante de erros de previsão, ou seja, quanto maior o valor de MEPA, menor acurácia.

$$
M E P=\left(\frac{\mathrm{I}}{n}\right) \times \sum_{i=1}^{n} \operatorname{Err} \operatorname{Pr} e v \text { e } M E P A=\left(\frac{\mathrm{I}}{n}\right) \times \sum_{i=1}^{n}|\operatorname{Err} \operatorname{Pr} e v|
$$

No entanto, com o intuito de facilitar a interpretação dos coeficientes das regressões, multiplicou-se o valor de MEPA por (-I) e obteve-se a variável APCA_N. Dessa forma, quanto mais próximo de zero for o valor dessa variável, menor será o montante de erros de previsão, ou seja, quanto maior o valor de APCA_N, maior acurácia. Conforme apresentado, a seguir.

$$
A P C A \_N=(-I) M E P A
$$

Multiplicando o valor de MEPA por (-I), tem-se uma medida que aumenta quando a acurácia de previsão é maior. Sendo assim, um atributo da empresa que está negativamente associado com a acurácia sinaliza previsões menos precisas e acuradas.

- Acurácia da previsão do consenso dos analistas (APCA_I): medida de acordo com a literatura internacional (DURU; REEB, 2002; LANG; LUNDHOLM, I996; BHAT et al., 2006; BYARD; LI; WEINTROP, 2006), como o negativo do valor absoluto dos erros de previsão dos analistas (diferença entre a previsão consensual dos analistas e o lucro por ação real), deflacionado pelo preço da ação.

$$
\operatorname{ACURACIA}_{t}=(-\mathrm{I}) \frac{\left|L P A P R E V_{i, t}^{t-\mathrm{I}}-\operatorname{LPAREAL}_{i, t}\right|}{P_{i, t-\mathrm{I}}}
$$


Em que: $L P A P R E V_{i, t}^{t-1}=$ lucro por ação previsto pelo consenso dos analistas no tempo t-I para a empresa i para o tempo t; $L P A R E A L_{i, t}=$ lucro por ação efetivo da empresa i apurado no tempo t; e $P_{i, t-I}=$ preço da ação da empresa no tempo $\mathrm{t}-\mathrm{I}$.

\subsubsection{Variáveis independentes}

- Práticas diferenciadas de governança corporativa (DBOV_Ni; DBOV_N2; DBOV_NM): compreende um conjunto de três variáveis binárias (dummies) que representam os três níveis diferenciados de governança corporativa da BM\&FBovespa (Nível I, Nível 2 e Novo Mercado, respectivamente). As variáveis assumem valor igual a I quando a empresa participa de algum nível diferenciado da BM\&FBovespa e igual a o quando não participa.

\subsubsection{Validade e justificativa da utilização dos níveis diferenciados de governança corporativa da BM\&FBovespa}

A segmentação especial de listagem é uma realidade no mercado brasileiro e os níveis diferenciados de governança corporativa da BM\&FBovespa (Nível, I, Nível 2 e Novo Mercado) são dados públicos e acessíveis a qualquer usuário, inclusive aos analistas de investimento do mercado. Além disso, os níveis da BM\&Bovespa já foram utilizados como proxies para práticas diferenciadas de governança em outras pesquisas realizadas no mercado brasileiro (ALENCAR, 2005; TERRA; LIMA, 2006; ANTUNES; MENDONÇA, 2008; SARLO NETO, 2009).

\subsubsection{Variáveis de controle da acurácia da previsão consensual dos analistas}

As variáveis de controle foram adicionadas aos modelos com o intuito de isolar o seu efeito sobre a variável dependente. Com base na revisão da literatura nacional e internacional a respeito dos determinantes da acurácia da previsão consensual dos analistas de mercado, apresentam-se as variáveis de controle utilizadas nos modelos.

- Idade da previsão (IDADE): número de dias entre a data da previsão e a data do anúncio do resultado real. De acordo com a literatura, há evidências de que quanto maior a idade da previsão, menor a acurácia (SILVA, I998; CLEMENT, I999; MARTINEZ, 2004; BYARD; LI; WEINTROP, 2006). 
- Viés da previsão (DOTIM): variável binária (dummy) que captura o viés da previsão. Essa variável assume valor igual a i quando a previsão é otimista e o quando é pessimista (SILVA, I998; MARTINEZ; SALIM, 2004; MARTINEZ, 2004).

- $\quad$ Resultado (DRESULT): variável binária $(d u m m y)$ que representa o resultado da empresa num determinado período (lucro ou prejuízo). Essa variável assume valor igual a I quando o resultado real da empresa é prejuízo e o quando este é lucro. De acordo com a literatura, há evidências de que, se o resultado é prejuízo, a acurácia da previsão é menor (SILVA, I998; ABARBANELL; LEHAVY, 2003; MARTINEZ; SALIM, 2004; MARTINEZ, 2004; BYARD; LI; WEINTROP, 2006; BHAT et al., 2006).

- Volatilidade dos resultados (DVPRESULT): desvio padrão dos resultados reais, ou seja, desvio padrão do lucro por ação do ano t mais os quatro anos anteriores ao da observação, escalonado pelo preço da ação da empresa i no período t. De acordo com a literatura, há evidências de que quanto maior for a volatilidade dos resultados, menor será a acurácia (SILVA, I998; BYARD; LI; WEINTROP, 2006; BHAT et al., 2006).

- Cobertura dos analistas (QANALIST): consiste na quantidade de analistas que acompanham a empresa i no período t. De acordo com a literatura, há evidências de que quanto maior for o número de analistas que acompanham uma determinada empresa, maior será a acurácia (CONROY; HARRIS, I987; BROWN, I997; MARTINEZ; SALIM, 2004; MARTINEZ, 2004).

- Dispersão das estimativas (DVPESTIMAT): medida de risco, calculada como desvio padrão das estimativas (previsões) para a empresa i no período $t$, escalonado pelo preço da ação da empresa i no período t. De acordo com a literatura, há evidências de que quanto maior a dispersão das estimativas, menor a acurácia (CONROY; HARRIS, I987; MARTINEZ; SALIM, 2004; MARTINEZ, 2004; BYARD; LI; WEINTROP, 2006).

- Tamanho (TAM): utilizou-se o logaritmo natural do valor de mercado da empresa como proxy para tamanho. Valor de mercado total da empresa, numa unidade monetária constante, apurado por meio da base de dados do Economática ${ }^{\circledR}$, para or/or de cada ano, com 90 dias de tolerância. De acordo com a literatura, há evidências de que quanto maior o tamanho da empresa analisada, maior a acurácia (BROWN, I997; RICHARDSON; TEOH; WYSOCKI, I999; MARTINEZ; SALIM, 2004; MARTINEZ, 2004; CHIANG; CHIA, 2005; BHAT et al., 2006).

- $\quad$ Price-to-book (PTB): relação entre o valor de mercado e o valor patrimonial da empresa i no tempo t. De acordo com a literatura, há evidências de que quanto maior o price-to-book, maior a acurácia (RICHARDSON; TEOH; WYSOCKI, I999; MARTINEZ, 2004). 
- Ano (DANO): variável dummy para capturar as particularidades de cada ano. Representada por um conjunto de variáveis binárias (dummies), que assumem valor igual a i para determinado ano e igual a o para os outros anos. De acordo com a literatura (MARTINEZ, 2004; BHAT et al., 2006; BYARD; LI; WEINTROP, 2006), as particularidades de cada ano influenciam na acurácia.

- $\quad$ Setor de atividade (DSETOR): representado por um conjunto de variáveis binárias (dummies), que assumem valor igual a i para as empresas que participam de determinado setor e igual a o para as empresas de outros setores, de acordo com a literatura (SILVA, I998; MARTINEZ, 2004, BHAT et al., 2006; BYARD; LI; WEINTROP, 2006).

\subsection{BASES DE DADOS}

Os dados e as informações utilizados na pesquisa foram coletados a partir das fontes apresentadas no Quadro I.

\section{QUADRO I}

FONTES DOS DADOS UTILIZADOS NA PESQUISA

\begin{tabular}{ll}
\hline DADOS & FONTES \\
\hline $\begin{array}{l}\text { Previsões dos analistas de empresas brasileiras } \\
\text { de capital aberto }\end{array}$ & $\begin{array}{l}\text { Banco de dados do sistema Thomson ONE } \\
\text { Analytics }^{\circledR}\end{array}$ \\
\hline $\begin{array}{l}\text { Econômico-financeiros e de mercado das } \\
\text { empresas brasileiras de capital aberto }\end{array}$ & Banco de dados do sistema Economática $^{\circledR}$ \\
\hline $\begin{array}{l}\text { Práticas diferenciadas de governança } \\
\text { corporativa das empresas brasileiras de } \\
\text { capital aberto }\end{array}$ & $\begin{array}{l}\text { Site da BM\&Fovespa } \\
\text { (www.bmfbovespa.com.br) }\end{array}$ \\
\hline
\end{tabular}

Fonte: Elaborado pelos autores.

\subsection{MODELOS}

A fim de atingir o objetivo de investigar a influência da adoção de práticas diferenciadas de governança corporativa sobre a acurácia das previsões do consenso dos analistas de mercado, foi utilizada a abordagem de efeitos fixos para 
o modelo de regressão com uso de dados em painel. Os modelos apresentados nesta seção baseiam-se numa relação linear entre as variáveis. O relacionamento entre a adoção de práticas diferenciadas de governança corporativa e a acurácia das previsões dos analistas de mercado pode ser expresso por:

$$
A_{C U R A C I A_{i, t}}=\alpha_{\circ}+\alpha_{\mathrm{I}} \operatorname{PGOV}_{i, t}+\sum_{j}^{K} \varpi_{j} V C_{i, t}^{j}+a_{i}+\xi_{i, t}
$$

Em que: $A C U R A C I A_{i, t}=$ acurácia da previsão do consenso dos analistas para a empresa i no período t. Essa variável será representada por APCA_N (de acordo com a literatura nacional) e por APCA_I (de acordo com a literatura internacional). $P G O V_{i, t}=$ variável independente que representa a adoção de práticas diferenciadas de governança corporativa pela empresa i no período t. Essa variável será representada pelo conjunto de dummies (DBOV_Ni; DBOV_N2; DBOV_NM); $V C_{i, t}^{j}=$ variáveis de controle $\mathrm{j}$, de um total de $\mathrm{k}$ variáveis, para a empresa i no período $t ; a_{i}$ representa os efeitos específicos não observáveis para a empresa i; $\xi_{i, t}$ representa o termo de erro do modelo.

O coeficiente $\alpha_{\mathrm{I}}$ representa a relação entre adoção de práticas diferenciadas de governança corporativa e a acurácia das previsões dos analistas. Se o valor estimado para o parâmetro for positivo e estatisticamente significante, será uma indicação de que as variáveis que representam a adoção de práticas diferenciadas de governança corporativa proporcionam um aumento na acurácia das previsões do consenso dos analistas de investimento do mercado brasileiro. Entretanto, caso o valor estimado para o parâmetro seja negativo e estatisticamente significante, será uma indicação de redução da acurácia.

Considerando que o modelo pode apresentar heterocedasticidade, ele foi estimado utilizando-se o método de regressão robusta ${ }^{8}$, por meio da inserção da matriz de White, "que procura detectar e corrigir situações de heterocedasticidade dos termos de perturbação" (FÁVERO et al., 2009, p. 393). Para definição do modelo de dados em painel mais apropriado para ser utilizado, foram aplicados os testes de Breusch-Pagan, de Hausman e de Chow, de acordo com as especificações de cada teste. De acordo com os testes, a abordagem dos efeitos fixos foi a mais apropriada.

Pela abordagem dos efeitos fixos, os interceptos das cross-sections variam, entretanto os coeficientes angulares são constantes entre elas, ou seja, os efeitos temporais não influenciam na regressão, apenas os individuais. Esses efeitos in-

A fim de corrigir problemas de presença de heterocedasticidade, Wooldridge (2006) sugere o uso de uma estatística t robusta. 
dividuais podem ser observáveis ou não e estão, normalmente, correlacionados com os regressores, ou seja, existe correlação entre os efeitos não observáveis e as variáveis.

\subsubsection{Modelo APCA_N}

No modelo APCA_N, a acurácia da previsão do consenso dos analistas é mensurada de acordo com a literatura nacional (MARTINEZ; SALIM, 2004; MARTINEZ, 2004) e representada pela variável APCA_N, e a adoção de práticas diferenciadas de governança corporativa é representada pelo conjunto de dummies (DBOV_NI; DBOV_N2; DBOV_NM). Desenvolvido a partir do modelo geral, esse modelo pode ser representado pela seguinte equação:

$$
\begin{gathered}
A P C A \_N_{i, t}=\alpha_{\circ}+\alpha_{\mathrm{I}} D B O V \_N \mathrm{I}_{i, t}+\alpha_{2} D B O V_{-} N 2_{i, t}+\alpha_{3} D B O V \_N M_{i, t}+ \\
+\sum_{j=1}^{8} \varpi_{j} V C_{i, t}^{j}+\sum_{a=2}^{9} \delta_{a} d a_{i, t}+\sum_{s=2}^{\mathrm{r} 9} \gamma_{s} d s_{i, t}+a_{i}+\xi_{i, t}
\end{gathered}
$$

Em que: $A P C A \_N_{i t}=$ acurácia da previsão de consenso dos analistas da empresa i no período t; $A P C A \_N_{i t}=$ variável dummy que assume valor igual a I quando a empresa i no período t participa do Nível i da BM\&FBovespa e igual a o quando não participa; $D B O V \_N 2_{i t}=$ variável dummy que assume valor igual a I quando a empresa i no período t participa do Nível 2 da BM\&FBovespa e igual a o quando não participa; $D B O V \_N M_{i t}=$ variável dummy que assume valor igual a I quando a empresa i no período t participa do novo mercado da BM\&FBovespa e igual a $\circ$ quando não participa; $V C_{i t}^{j}=$ variáveis de controle $\mathrm{j}$, de um total de $\mathrm{k}$ variáveis, para a empresa i no período t; $d a_{i t}=$ DANO, variável dummy que assume valor igual a I para determinado ano e igual a o para os outros anos; $d s_{i t}=$ DSETOR, variável dummy que assume valor igual a i para as empresas que participam de determinado setor e igual a $\circ$ para as empresas de outros setores; $a_{i}$ representa os efeitos específicos não observáveis para a empresa $i ; \xi_{i, t}$ representa o termo de erro do modelo.

\subsubsection{Modelo APCA_I}

No modelo APCA_I, a acurácia da previsão do consenso dos analistas é mensurada de acordo com a literatura internacional (DURU; REEB, 2002; LANG; LUNDHOLM, I996; BHAT et al., 2006; BYARD; LI; WEINTROP, 2006) e representada pela variável APCA_I, e a adoção de práticas diferenciadas de 
governança corporativa é representada pelo conjunto de dummies (DBOV_NI; DBOV_N2; DBOV_NM). Desenvolvido a partir do modelo geral, esse modelo pode ser representado pela seguinte equação:

$$
\begin{aligned}
A P C A \_I_{i, t}=\alpha_{\circ} & +\alpha_{\mathrm{I}} D B O V \_N \mathrm{I}_{i, t}+\alpha_{2} D B O V \_N 2_{i, t}+\alpha_{3} D B O V \_N M_{i, t}+ \\
& +\sum_{j=1}^{8} \varpi_{j} V C_{i, t}^{j}+\sum_{a=2}^{9} \delta_{a} d a_{i, t}+\sum_{s=2}^{\mathrm{I} 9} \gamma_{s} d s_{i, t}+a_{i}+\xi_{i, t}
\end{aligned}
$$

Em que: $A P C A_{-} I_{i t}=$ acurácia da previsão de consenso dos analistas da empresa i no período t. As demais variáveis são as mesmas utilizadas no modelo APCA_N.

\subsection{RESULTADOS ESPERADOS}

Considerando a plataforma teórica desenvolvida sobre como a adoção de práticas diferenciadas de governança corporativa pode ser considerada um elemento sinalizador da estrutura informacional das empresas ao mercado de capitais brasileiro e as evidências encontradas nos trabalhos de Chiang e Chia (2005), Bhat et al. (2006) e Byard, Li e Weintrop, (2006), espera-se que seja possível avaliar a eficácia da adoção dessas práticas na acurácia das previsões feitas pelos analistas de investimento do mercado brasileiro.

É possível esperar que a adoção de práticas diferenciadas de governança corporativa tenha uma influência positiva na acurácia da previsão (do consenso e individual) dos analistas de investimento do mercado brasileiro. Espera-se que os coeficientes $\alpha_{\mathrm{T}}, \alpha_{2}$ e $\alpha_{3}$ das variáveis DBOV_NI, DBOV_N2 e DBOV_NM, nos modelos APCA_N e APCA_I, sejam positivos e estatisticamente significantes.

\section{APRESENTAÇÃo e ANÁlise dos RESULTADOS}

\section{ESTATÍSTICA DESCRITIVA}

De acordo com os procedimentos descritos na metodologia e a partir dos dados coletados de suas respectivas fontes, são apresentadas, na Tabela I, as estatísticas descritivas das variáveis utilizadas nos modelos de acurácia das previsões do consenso dos analistas de mercado. 
TABELA I

ESTATISTICA DESCRITIVA DAS VARIÁVEIS

\begin{tabular}{ccccc}
\hline VARIÁVEL & MÉDIA & DESVIO PADRÃO & MÍNIMO & MÁXIMO \\
\hline APCA_N & $-0,35$ & 0,43 & $-4,46$ & $-0,02$ \\
\hline APCA_I & $-4,90$ & 15,11 & $-226,10$ & 0,00 \\
\hline DBOV_N1 & - & - & 0,00 & 1,00 \\
\hline DBOV_N2 & - & - & 0,00 & 1,00 \\
\hline DBOV_NM & - & - & 0,00 & 1,00 \\
\hline IDADE & 89,64 & 70,12 & 0,00 & 440,00 \\
\hline DOTIM & - & - & 0,00 & 1,00 \\
\hline DRESULT & - & - & 0,00 & 1,00 \\
\hline DVPRESULT & 13,37 & 33,83 & 0,00 & 286,59 \\
\hline QANALIST & 7,09 & 2,65 & 2,00 & 14,00 \\
\hline DVPESTIMAT & 5,57 & 17,57 & 0,00 & 252,19 \\
\hline TAM & 22,61 & 1,25 & 18,93 & 26,74 \\
\hline PTB & 3,06 & 3,73 & $-11,35$ & 40,27 \\
\hline
\end{tabular}

Fonte: Elaborada pelos autores.

Pelos dados apresentados na Tabela I, observa-se, por meio das medidas de acurácia (APCA_N, APCA_I), um distanciamento entre os valores previstos pelos analistas e os valores realizados pelas empresas. Em relação ao nível de governança corporativa, observa-se que ainda existem companhias, no Brasil, que não pertencem a um dos segmentos diferenciados de governança da BM\&FBovespa (DBOV_NI, DBOV_N2, DBOV_NM), confirmando que o mercado brasileiro é caracterizado por um ambiente de fraca proteção ao investidor, principalmente em virtude da concentração acionária e carência de defesa dos direitos dos acionistas minoritários.

\subsection{PRÁTICAS DIFERENCIADAS DE GOVERNANÇA CORPORATIVA}

As variáveis DBOV_NI, DBOV_N2 e DBOV_NM representam a adoção de práticas diferenciadas de governança corporativa. Portanto, a seguir, apresenta-se 
uma análise das proxies de governança que compõem a amostra de trabalho desta pesquisa.

Na Tabela 2, pode-se observar a segmentação das observações ${ }^{9}$ da amostra de trabalho em função dos níveis diferenciados de governança corporativa da BM\&FBovespa. Pelos dados apresentados, verifica-se que 33,25\% das observações representam as empresas que não aderiram a qualquer um dos níveis diferenciados de governança da BM\&FBovespa, entretanto 66,75\% das observações representam as empresas que aderiram a algum segmento da BM\&FBovespa (Nível I, Nível 2 e Novo Mercado). O Nível i da BM\&FBovespa é o segmento que apresenta o maior percentual de observações da amostra (34,57\%), seguido pelo Novo Mercado (25,I7\%) e pelo Nível 2 (7,02\%).

\section{TABELA 2}

OBSERVAÇÕES SEGMENTADAS PELOS NÍVEIS DIFERENCIADOS DE GOVERNANÇA CORPORATIVA DA BM\&FBOVESPA

\begin{tabular}{ccccccc}
\hline & \multicolumn{5}{c}{ OBSERVAÇÕES } \\
\cline { 2 - 7 } ANOS & TRADICIONAL & NIVEL 1 & NIVEL 2 & NOVO MERCADO & TOTAL & $\%$ \\
\hline 2000 & 18 & 0 & 0 & 0 & 18 & 0,77 \\
\hline 2001 & 42 & 14 & 0 & 8 & 64 & 2,72 \\
\hline 2002 & 30 & 18 & 0 & 10 & 58 & 2,47 \\
\hline 2003 & 104 & 77 & 6 & 17 & 204 & 8,67 \\
\hline 2004 & 172 & 136 & 7 & 24 & 339 & 14,41 \\
\hline 2005 & 106 & 110 & 28 & 50 & 294 & 12,50 \\
\hline 2006 & 128 & 143 & 46 & 123 & 440 & 18,71 \\
\hline 2007 & 106 & 158 & 37 & 193 & 494 & 21,00 \\
\hline 2008 & 76 & 157 & 41 & 167 & 441 & 18,75 \\
\hline Amostra & 782 & 813 & 165 & 592 & 2.352 & 100,00 \\
\hline$\%$ & 33,25 & 34,57 & 7,02 & 25,17 & 100,00 & \\
\hline
\end{tabular}

Fonte: Elaborada pelos autores.

9 Em cada observação, considera-se a previsão do analista i para a empresa $j$ no ano t. 
Os dados apresentados na Tabela 2 sugerem que as empresas acompanhadas pelos analistas de investimento do mercado brasileiro, em sua maioria, são aquelas pertencentes a algum nível diferenciado de governança corporativa da BM\&FBovespa.

\subsection{VIÉS E ACURÁCIA DAS PREVISÕES DO CONSENSO DE ANALISTAS}

Apesar de o viés das previsões dos analistas não ser uma variável analisada nos modelos ${ }^{\mathrm{IO}}$, vale destacar que, na média, as previsões do consenso de analistas de investimento do mercado brasileiro, que compuseram a amostra de trabalho, têm um viés otimista, conforme evidências já encontradas na literatura nacional (SILVA, I998; FRANCO, 2002; MARTINEZ; SALIM, 2004; MARTINEZ, 2004) e na literatura internacional (SCHIPPER, I99I; BROWN, I996, I998; LIM, I998; RICHARDSON; TEOH; WYSOCKI, I999; DECHOW; HUTTON; SLOAN, 2000; KOTHARI, 200I; BEAVER, 2002; GU; WU, 2003; ABARBANELL; LEHAVY, 2003; DECHOW; SCHRAND, 2004).

Na Tabela 3, pode-se observar o comportamento médio, em cada ano, do viés e da acurácia das previsões do consenso de analistas, mensurados a partir da metodologia proposta por Martinez e Salim (2004) e Martinez (2004).

\section{TABELA 3}

VIÉS E ACURACIA DAS PREVISÕES DO CONSENSO DE ANALISTAS

\begin{tabular}{cccc}
\hline ANO & APCA_N & MEP & VIÉS \\
\hline 2000 & $-0,1977$ & $-0,1356$ & Otimista \\
\hline 2001 & $-0,5545$ & 0,4475 & Pessimista \\
\hline 2002 & $-0,5605$ & $-0,1975$ & Otimista \\
\hline 2003 & $-0,2958$ & $-0,0170$ & Otimista \\
\hline 2004 & $-0,2942$ & $-0,0650$ & Otimista \\
\hline 2005 & $-0,2867$ & $-0,0743$ & Otimista \\
\hline 2006 & $-0,3525$ & $-0,1840$ & Otimista \\
\hline 2007 & $-0,2989$ & $-0,1145$ & Otimista \\
\hline 2008 & $-0,4456$ & $-0,3168$ & Otimista \\
\hline
\end{tabular}

Fonte: Elaborada pelos autores.

Io Nos modelos de acurácia das previsões do consenso de analistas, utilizou-se, apenas, a variável $d u m m y$ DOTIM, que assume valor igual a I, quando a previsão é otimista, e igual a o, quando a previsão é pessimista. 
Percebe-se que os analistas de empresas brasileiras foram otimistas (MEP), em termos médios, mas tiveram um desempenho fraco em relação à acurácia de suas previsões (APCA_N), pois quanto mais distante de zero for o valor da variável, maior será o montante de erros de previsão computados.

\section{RELAÇÃO ENTRE A ADOÇÃO DE PRÁTICAS DIFERENCIADAS DE GOVERNANÇA CORPORATIVA E A ACURÁCIA DAS PREVISÕES DO CONSENSO DOS ANALISTAS}

A análise da acurácia das previsões foi feita a partir do consenso dos analistas. Segundo Martinez (2004, p. 42), "a análise do consenso fundamenta-se na idéia de que a representação das expectativas do mercado pode ser obtida por uma medida de tendência central da distribuição das projeções dos analistas". O consenso dos analistas reduz os erros de previsão e tem melhor desempenho que as previsões individuais dos analistas (BEAVER, I98I; CONROY; HARRIS, I987). Adicionalmente, o uso de um consenso reduz o risco de escolher, impropriamente, uma única previsão (CONROY; HARRIS, I987). No entanto, similarmente ao estudo de Richardson, Teoh e Wysocki (I999), foram utilizadas as previsões individuais dos analistas para calcular as previsões do consenso.

\subsubsection{Modelo APCA_N}

A partir do modelo APCA_N, buscou-se verificar se a variável APCA_N, que representa a acurácia da previsão do consenso dos analistas, mensurada de acordo com a literatura nacional (MARTINEZ; SALIM, 2004; MARTINEZ, 2004), é influenciada pela adoção de práticas diferenciadas de governança corporativa, representada pelo conjunto de variáveis dummies (DBOV_NI; DBOV_N2; DBOV_NM).

De acordo com os resultados, apresentados na Tabela 4, as variáveis DBOV Nı, DBOV_N2 não foram estatisticamente significantes no modelo APCA_N pela abordagem dos efeitos fixos, entretanto a variável DBOV_NM apresentou coeficiente positivo (O,IO8I) e significante (I\%), indicando uma relação positiva entre a adoção de governança conforme as exigências do segmento Novo Mercado da BM\&FBovespa e a acurácia das previsões do consenso dos analistas de investimento do mercado brasileiro. 


\section{TABELA 4}

RESULTADOS DO MODELO APCA_N

\begin{tabular}{lcc}
\hline \multicolumn{1}{c}{ VARIÁVEL DEPENDENTE: APCA_N E VARIÁVEL INDEPENDENTE: DBOV_N1, DBOV_N2, DBOV_NM } \\
\hline & EFEITOS FIXOS & \\
\hline CONS & $1,8415^{*}$ & $(0,6284)$ \\
\hline DBOV_N1 & 0,0264 & $(0,0322)$ \\
\hline DBOV_N2 & 0,2117 & $(0,1324)$ \\
\hline DBOV_NM & $0,1081^{*}$ & $(0,0247)$ \\
\hline \multicolumn{1}{c}{ VARIÁVEIS DE CONTROLE } & & $(0,0001)$ \\
\hline IDADE & 0,0000 & $(0,0122)$ \\
\hline DOTIM & $-0,0758^{*}$ & $(0,0554)$ \\
\hline DRESULT & $-0,7107^{*}$ & $(0,0004)$ \\
\hline DVPRESULT & $-0,0002$ & $(0,0062)$ \\
\hline QANALIST & 0,0095 & $(0,0006)$ \\
\hline DVPESTIMAT & $-0,0009$ & $(0,0300)$ \\
\hline TAM & $-0,0964^{*}$ & $(0,0076)$ \\
\hline PTB & $0,0161 * *$ & \\
\hline Dummy ANO & $35,53^{*}$ & \\
\hline n. Obs. & $24,33 \%$ & \\
\hline EStatística-F & & \\
\hline ajust. & & \\
\hline
\end{tabular}

Notas: (I) Os asteriscos indicam o nível de significância dos coeficientes: *(I\%), *** (5\%) e ****(IO\%). (2) Para dummies ano e setor, "sim" significa que pelo menos uma foi significante, e "não", o oposto. (3) Os valores entre parênteses indicam o erro padrão robusto dos coeficientes.

Fonte: Elaborada pelos autores.

O resultado da estatística-F, pela abordagem dos efeitos fixos, apresentou valor $(35,53)$ significante $(\mathrm{r} \%)$, rejeitando a hipótese nula de que os coeficientes são conjuntamente iguais a zero. Quando se analisa o impacto das variáveis de 
controle na acurácia das previsões do consenso dos analistas de investimento do mercado brasileiro, observam-se os seguintes fatores:

- Previsões otimistas (DOTIM) são menos acuradas, contrariando as evidências encontradas por Silva (I998), Martinez e Salim (2004) e Martinez (2004).

- Para empresas com prejuízo (DRESULT), as previsões são menos acuradas, conforme as evidências já encontradas por Silva (I998), Abarbanell e Lehavy (2003), Martinez e Salim (2004), Martinez (2004), Byard, Li e Weintrop (2006) e Bhat et al. (2006).

- A variável TAM apresentou valor negativo e significante (І\%), indicando que quanto maior a empresa, menor a acurácia. Evidências contrárias foram encontradas por Brown (I997), Richardson, Teoh e Wysocki (I999), Martinez e Salim (2004), Martinez (2004), Chiang e Chia (2005) e Bhat et al. (2006).

- A variável PTB apresentou valor positivo e significante $(5 \%)$, indicando que quanto maior o price-to-book da empresa, maior a acurácia, o que corrobora os achados de Richardson, Teoh e Wysocki (I999) e Martinez (2004).

- As variáveis IDADE, DVPRESULT, QANALIST e DVPESTIMAT não foram estatisticamente significantes.

Pelos resultados apresentados, confirmou-se parcialmente a hipótese de que a adoção de práticas diferenciadas de governança corporativa influencia positivamente a acurácia das previsões do consenso dos analistas de investimento do mercado brasileiro. Verificou-se que, para as empresas pertencentes ao segmento do Novo Mercado da BM\&FBovespa, as previsões dos analistas são mais acuradas. Vale destacar que o Novo Mercado é caracterizado pela exigência de um nível de governança corporativa das empresas de capital aberto, o que vai além do exigido pela legislação. Segundo a BM\&FBovespa (2008), a valorização das ações é influenciada pela segurança da qualidade demonstrada pelas empresas. Além disso, destaca que o Novo Mercado tem como diferenciais a maior credibilidade e a transparência nas informações prestadas pelas empresas.

\section{4..2 Modelo APCA_I}

A utilização do modelo APCA_I objetivou verificar se a adoção de práticas diferenciadas de governança corporativa, representada pelo conjunto de variáveis dummies (DBOV_NI; DBOV_N2; DBOV_NM), influencia a acurácia da previsão do consenso dos analistas, representada pela variável APCA_I e mensurada de acordo com a literatura internacional (DURU; REEB, 2002; LANG; LUNDHOLM, I996; BHAT et al., 2006; BYARD; LI; WEINTROP, 2006). 


\section{TABELA 5}

RESULTADOS DO MODELO APCA_I

\begin{tabular}{|c|c|c|}
\hline \multicolumn{3}{|c|}{ EFEITOS FIXOS } \\
\hline CONS & $52,7850 *$ & $(20,4438)$ \\
\hline DBOV_N1 & $-0,8109$ & $(1,1570)$ \\
\hline DBOV_N2 & $9,1127 * * *$ & $(4,7250)$ \\
\hline DBOV_NM & 2,0125 & $(1,7728)$ \\
\hline \multicolumn{3}{|c|}{ VARIÁVEIS CONTROLE } \\
\hline IDADE & $-0,0028$ & $(0,0020)$ \\
\hline DOTIM & 0,4817 & $(0,3311)$ \\
\hline DRESULT & $-4,1221 *$ & $(1,1415)$ \\
\hline DVPRESULT & $0,0672 *$ & $(0,0192)$ \\
\hline QANALIST & $0,3355 * *$ & $(0,1491)$ \\
\hline DVPESTIMAT & $-0,7502^{*}$ & $(0,0518)$ \\
\hline TAM & $-2,1963$ ** & $(0,8915)$ \\
\hline PTB & 0,0281 & $(0,0456)$ \\
\hline Dummy ANO & Sim & \\
\hline n. Obs. & 2.352 & \\
\hline Estatística-F & $49,53 *$ & \\
\hline $\mathrm{R}^{2}$ ajust. & $60,82 \%$ & \\
\hline
\end{tabular}

Notas: (I) Os asteriscos indicam o nível de significância dos coeficientes: *(I\%), ***(5\%) e ****(IO\%). (2) Para dummies ano e setor, "sim" significa que pelo menos uma foi significante, e "não", o oposto. (3) Os valores entre parênteses indicam o erro padrão robusto dos coeficientes.

Fonte: Elaborada pelos autores.

Conforme observado na Tabela 5, o resultado da estatística-F, pela abordagem dos efeitos fixos, apresentou valor $(49,53)$ significante (I\%), rejeitando a hipótese nula de que os coeficientes são conjuntamente iguais a zero. Quando se analisa o 
impacto das variáveis de controle na acurácia das previsões do consenso dos analistas de investimento do mercado brasileiro, observam-se os seguintes fatores:

- Para empresas com prejuízo (DRESULT), as previsões são menos acuradas, conforme as evidências já encontradas por Silva (I998), Abarbanell e Lehavy (2003), Martinez e Salim (2004), Martinez (2004), Byard, Li e Weintrop (2006) e Bhat et al. (2006).

- A variável DVPRESULT apresentou valor positivo e significante (I\%), ou seja, quanto maior o desvio padrão dos resultados, maior a acurácia do consenso. Evidências contrárias foram encontradas por Silva (I998), Byard, Li e Weintrop (2006) e Bhat et al. (2006).

- A variável QANALIST apresentou valor positivo e significante (5\%), ou seja, quanto maior o número de analistas que acompanham a empresa, maior a acurácia do consenso, o que corrobora os resultados de Conroy e Harris (I987), Brown (I997), Martinez e Salim (2004) e Martinez (2004).

- A variável DVPESTIMAT apresentou valor negativo e significante (ז\%), ou seja, quanto menor o desvio das estimativas, maior a acurácia, de acordo com as evidências apresentadas por Conroy e Harris (1987), Martinez e Salim (2004), Martinez (2004) e Byard, Li e Weintrop (2006).

- A variável TAM apresentou valor negativo e significante $(5 \%)$, indicando que quanto maior a empresa, menor a acurácia. Evidências contrárias foram encontradas por Brown (I997), Richardson, Teoh e Wysocki (I999), Martinez e Salim (2004), Martinez (2004), Chiang e Chia (2005) e Bhat et al. (2006).

- $\quad$ As variáveis IDADE, DOTIM e PTB não foram estatisticamente significantes.

Dessa forma, foi possível confirmar parcialmente que a adoção de práticas diferenciadas de governança corporativa influencia positivamente a acurácia das previsões do consenso dos analistas de investimento do mercado brasileiro, pois foi verificado que apenas para as empresas pertencentes ao segmento do Nível 2 da BM\&FBovespa as previsões dos analistas são mais acuradas.

\section{CONSIDERAÇÕES FINAIS}

O objetivo deste trabalho foi investigar, sob a perspectiva da teoria da sinalização, a influência da adoção de práticas diferenciadas de governança corporativa sobre a acurácia das previsões do consenso de analistas de investimento do mercado brasileiro. Buscou-se essa relação, pois, de acordo com Bhat et al. (2006), o estudo dos impactos da adoção de mecanismos e práticas de governança corporativa sobre as previsões dos analistas de mercado é um campo 
ainda inexplorado. Além disso, segundo Larcker, Richardson e Tuna (2007), não há uma teoria consolidada a respeito da natureza complexa e multidimensional da governança corporativa ou uma base conceitual para selecionar as características relevantes de governança para incluir em um estudo empírico. Portanto, em virtude dessa necessidade de fundamentação teórica para a governança corporativa, foram utilizados os pressupostos da teoria da sinalização (SPENCE, I973).

Sob a perspectiva da teoria da sinalização, considerou-se que a governança corporativa representa um sinal emitido pelas empresas ao mercado de capitais, capaz de influenciar a acurácia das previsões dos analistas de investimento do mercado brasileiro. Considerou-se que empresas dentro do mesmo ambiente contratual, institucional e cultural possam ter incentivos para sinalizar ao mercado que adotam práticas diferenciadas de governança corporativa e que os sinais emitidos, por meio dessa adoção, representam parâmetros na mudança da probabilidade condicional que definem as crenças, tanto dos analistas na elaboração de suas previsões e recomendações quanto dos investidores na escolha de seus investimentos.

Verificou-se que a adoção de práticas diferenciadas de governança corporativa tem uma influência positiva sobre a acurácia das previsões do consenso dos analistas de investimento do mercado brasileiro. No entanto, essa influência variou em função dos modelos utilizados. Pela utilização dos modelos APCA_N e APCA_I, observou-se um impacto positivo, porém isolado (em cada modelo), dos segmentos diferenciados da BM\&FBovespa, do Novo Mercado e do Nível 2, respectivamente. Essas evidências sugerem que quanto maior a exigência da BM\&FBovespa para adesão em um de seus segmentos diferenciados, maior o impacto dessas exigências na acurácia das previsões do consenso dos analistas de investimento do mercado brasileiro.

De acordo com a abordagem da teoria da sinalização de Spence (I973), caso não houvesse nenhuma correlação entre a adoção de práticas diferenciadas de governança corporativa (considerada como um sinal positivo) e a acurácia da previsão dos analistas de investimento, então poderia remeter-se à ideia de que a governança nunca poderia ser considerada um sinal eficaz, no sentido de se converter em informações úteis para o mercado, em especial para analistas de investimento e investidores, pois não existiriam diferenças entre as empresas que investem em governança e as que não investem.

Entretanto, a partir dos resultados obtidos, percebe-se que há evidências, no Brasil, de que a acurácia da previsão do consenso dos analistas é influenciada positivamente pelas práticas diferenciadas de governança corporativa adotadas pelas empresas e que os analistas de investimento podem estar assimilando o sinal (práticas diferenciadas de governança corporativa) emitido pelas empresas 
brasileiras, levando a uma previsão de lucros mais acurada. As evidências encontradas reafirmam a utilidade da governança corporativa para os analistas de investimento do mercado brasileiro.

Assim, como nas pesquisas de Chiang e Chia (2005), Bhat et al. (2006) e Byard, Li e Weintrop (2006), encontrou-se uma relação entre a governança e a acurácia das previsões dos analistas. Verificou-se que a governança corporativa pode ser considerada uma fonte de informação, pois ela afeta positivamente a qualidade dos números contábeis reportados, que são relevantes e significantes na previsão de lucros futuros. Há evidências de que a adoção de práticas diferenciadas de governança corporativa confere qualidade (confiabilidade e relevância) aos lucros reportados, e estes passam a ser bons indicadores da performance operacional futura e a refletir, ano após ano, o valor intrínseco da empresa (DECHOW; SCHRAND, 2004), favorecendo a acurácia das previsões feitas pelos analistas de investimento do mercado brasileiro, ou seja, favorecendo a exatidão dos resultados previstos.

Quando a empresa sinaliza mais informação para os outsiders, ela tende a eliminar a assimetria de informação (CHIANG; CHIA, 2005). Assim sendo, a adoção de práticas diferenciadas de governança corporativa reduz a assimetria informacional, reduz a incerteza sobre o futuro e pode contribuir para o aumento da confiança dos analistas e/ou investidores na empresa, além de favorecer a liquidez do mercado (BROWN; CAYLOR, 2004), como garantia de que não haja comprometimento do volume de negócios realizados no mercado.

Existem evidências de que empresas, também, têm incentivos para se destacar em um país como o Brasil, que possui características de ser um país com: tradição legal no código romano (code law); influência dos órgãos reguladores no estabelecimento de regras contábeis; modelo contábil continental; ambiente contábil e institucional fracos; sistema judiciário lento e ineficiente; alta participação do Estado na economia; baixo enforcement legal; alta concentração acionária; sistema financeiro orientado para o crédito; fraca proteção ao acionista; forte relação entre a contabilidade tributária e financeira; estrutura de governança fraca, em geral; mas com grandes oportunidades de investimento para as empresas brasileiras. As empresas em tais situações hostis podem se diferenciar para conseguir governança superior e relatórios mais informativos, no mesmo nível, geralmente, encontrado em países desenvolvidos. Além disso, podem proporcionar maior acurácia às previsões dos analistas.

Os resultados obtidos reforçam a importância das recomendações da BM\&FBovespa, da Comissão de Valores Mobiliários, do Banco Mundial, do Instituto Brasileiro de Governança Corporativa e outros sobre a necessidade de adoção de práticas diferenciadas de governança corporativa. Percebe-se que a governança, além de ter importância para analistas e investidores, no processo 
de avaliação das empresas, pode ter implicações positivas para outros agentes que atuam no mercado de capitais brasileiro.

De acordo com o Instituto Brasileiro de Governança Corporativa (2009), o segmento de Nível I caracteriza-se por exigir práticas adicionais de liquidez das ações e disclosure; as empresas do Nível 2 têm por obrigação práticas adicionais relativas aos direitos dos acionistas e conselho de administração; e o Novo Mercado diferencia-se pela exigência para emissão exclusiva de ações com direito a voto. As evidências encontradas neste trabalho suportam a ideia de que as companhias que aderem aos segmentos Nível 2 e Novo Mercado possam apresentar como resultado esperado redução das incertezas no processo de avaliação, investimento e de risco, aumento de investidores interessados e, consequentemente, o fortalecimento do mercado acionário, trazendo benefícios para investidores, empresas, mercado de capitais e Brasil. Além disso, o crescimento do mercado brasileiro, o aumento de novas empresas listando seu capital na BM\&FBovespa, o avanço do número de investidores e o aumento do volume de investimentos negociados na BM\&FBovespa ${ }^{\text {II }}$ reforçam a relevância da adoção de práticas diferenciadas de governança corporativa. Como a adoção dessas práticas reduz a assimetria informacional no mercado, possibilitando que os agentes financeiros tenham, ao mesmo tempo, informações de qualidade ${ }^{\mathrm{I2}}$, pode-se supor que os arranjos de governança venham, também, favorecer a eficiência do mercado, pois as informações e expectativas estariam refletidas correta e imediatamente nos preços dos ativos.

Algumas limitações de pesquisa devem ser consideradas, como o número limitado de empresas brasileiras de capital aberto acompanhadas por analistas de mercado e disponíveis no sistema da Thomson ONE Analytics ${ }^{\circledR}$. Portanto, a amostra foi selecionada de forma intencional, e não probabilística, entre aquelas empresas que eram acompanhadas por analistas e estavam disponíveis na base de dados do sistema Thomson ONE Analytics ${ }^{\circledR}$, de maneira que os resultados da pesquisa não podem ser generalizados para a população como um todo. As evidências se referem à amostra de trabalho utilizada.

Para novas pesquisas, sugere-se: analisar a intensidade do sinal emitido pelas empresas; investigar, junto aos analistas, a demanda pela quantidade e tipo de informação sobre governança; verificar a influência da adoção de práticas diferenciadas de governança corporativa nas recomendações feitas pelos analistas; investigar a influência da governança para agências de rating e para outras instituições no processo de avaliação das empresas.

II De acordo com dados da BM\&FBovespa (2009), o volume total negociado, em 2000 , foi de aproximadamente R\$ I85.I90,60 e, em 2008, de R\$ I.375.848,IO.

12 Relevantes e confiáveis. 


\section{AN ANALYSIS OF THE RELATIONSHIP BETWEEN CORPORATE GOVERNANCE AND ACCURACY OF THE ANALYSTS FORECASTS OF THE BRAZILIAN MARKET}

\section{ABSTRACT}

The aim of this paper is to investigate the perspective of signaling theory, influence the adoption of differentiated practices of corporate governance on the accuracy of consensus (average forecast earnings) forecasts of analysts of the Brazilian market. We investigated this relationship because of the lack of a well-developed theory about the complex and multidimensional nature of corporate governance. The accuracy of analyst's forecasts was measured from the proposed methodologies in national and international literature. As a proxy for adoption of differentiated corporate governance practices were used in different levels of corporate governance BM\&FBovespa (Level I, Level 2 and New Market). A working sample of the research was composed of I05 public companies with shares traded on the Stock Exchange of São Paulo who had regular coverage of industry analysts, over the period 2000 to 2008. We considered both financial institutions and non-financial, totaling 2352 observations. According to the results, there is evidence that corporate governance positively influences the accuracy of the forecasts of analysts. Thus, one can consider that the adoption of differentiated practices of corporate governance is a positive sign, issued by companies to the capital market, capable of influencing the accuracy of consensus forecasts of analysts of the Brazilian market, and that this signal represents the change in the parameters that define the conditional probability beliefs, both analysts in preparing their forecasts and recommendations for investors in choosing their investments. It is our understanding that this work contributes not only to the national and international literature as far as corporate governance and analysts' forecasts go, but also to the Brazilian capital market (analysts, investors, auditors, banks, investment institutions, rating agencies, pension funds, regulatory bodies, associations, stock exchange, companies themselves, managers, among others) when it shows the direct and indirect benefits of the adoption of distinctive practices of corporate governance by Brazilian companies.

\section{KEYWORDS}

Corporate governance; Accuracy; Forecasts; Analysts; Signaling. 


\section{UN ANÁLISIS DE LA RELACIÓN ENTRE EL GOBIERNO CORPORATIVO Y PRECISIÓN DE LAS PREVISIONES DE LOS ANALISTAS DE MERCADO BRASILEÑO}

\section{RESUMEN}

El objetivo de este trabajo es investigar la perspectiva de la teoría de señalización, influyen en la adopción de prácticas diferenciadas de gobierno corporativo en la exactitud de las previsiones de consenso (los ingresos medios previsión) de los analistas del mercado brasileño. Hemos investigado esta relación debido a la falta de una teoría bien desarrollada sobre la naturaleza compleja y multidimensional de la gestión empresarial. La precisión de las previsiones de los analistas se midió a partir de las metodologías propuestas en la literatura nacional e internacional. Como un proxy para la adopción de prácticas diferenciadas de gobierno corporativo se utilizaron en los diferentes niveles de gobierno corporativo de BM\&FBovespa (Nivel I, Nivel 2 y Nuevo Mercado). Una muestra de trabajo de la investigación se compone de I05 empresas públicas, con acciones negociadas en la Bolsa de Valores de São Paulo, que tuvo una cobertura regular de analistas de la industria, en el período 2000 a 2008 . Se consideraron tanto las instituciones financieras y no financieras, por un total de 2.352 observaciones. Según los resultados, hay evidencia de que la gobernanza empresarial influye positivamente en la exactitud de las previsiones de los analistas. Por lo tanto, se puede considerar que la adopción de prácticas diferenciadas de gobierno corporativo es un signo positivo, emitido por las empresas al mercado de capitales, capaces de influir en la exactitud de las previsiones de consenso de los analistas del mercado brasileño, y que esta señal representa el cambio en los parámetros que definen las creencias probabilidad condicionada, tanto los analistas en la preparación de sus previsiones y recomendaciones para los inversores en la elección de sus inversiones. Se entiende que este trabajo contribuye a la literatura sobre el gobierno corporativo y las previsiones de los analistas, sino también para el mercado de capitales brasileño (analistas, inversores, auditores, bancos, instituciones de inversión, agencias de calificación, fondos reguladores de pensiones, asociaciones, bolsas de valores, empresas propias, gerentes, entre otros), para demostrar los beneficios directos e indirectos de la adopción de prácticas de (134) gobierno corporativo de las empresas brasileñas.

\section{palabras clave}

Gobierno corporativo; Precisión; Pronósticos; Analistas; Señalización. 


\section{REFERÊNCIAS}

ABARBANELL, J.; BUSHEE, B. J. Fundamental analysis, future earnings, and stock prices. Journal of Accounting Research, v. 35, n. I, p. I-24, I997.

ABARBANELL, J.; LEHAVY, R. An explanation for why prior stock returns and analysts' earnings forecast revisions predict earnings management and forecast errors. Working Paper. 2003. Disponível em: <http://webuser.bus.umich.edu/rlehavy/ALBiasExplanationo5-23-03.pdf>. Acesso em: I8 ago. 2008.

AKERLOF, G. The market for "lemons": qualitative uncertainly and the market mechanism. Quarterly Journal of Economics, v. 84, p. 488-500, I970.

ALENCAR, R. C. Custo de capital próprio e nível de disclosure nas empresas brasileiras. BBR. Brazilian Business Review, Vitória, v. 2, n. I, p. I-I2, 2005.

ALENCAR, R. C. de. Nivel de disclosure e custo de capital próprio no mercado brasileiro. 2007. Tese (Doutorado em Controladoria e Contabilidade)-Faculdade de Economia, Administração e Contabilidade, Universidade de São Paulo, São Paulo, 2007.

ALI, A.; HWANG, L. S. Country-specific factors related to financial reporting and the value relevance of accounting data. Journal of Accounting Research, v. 38, n. I, p. I-2I, 2000.

ANTUNES, G. A.; MENDONÇA; M. M. de. Impacto da adesão aos níveis de governança da Bovespa na qualidade de informação contábil: uma investigação acerca da oportunidade, relevância e do conservadorismo contábil utilizando dados em painel. In: CONGRESSO DA ASSOCIAÇÃO NACIONAL DOS PROGRAMAS DE PÓS-GRADUAÇÃO EM CIÊNCIAS CONTÁBEIS, 2., 2008, Salvador. Anais... Salvador: Anpcont, 2008. I CD-ROM.

BALL, R. et al. The effect of international institutional factors on properties of accounting earnings. Journal of Accounting and Economics, n. 29, p. I-5I, 2000.

BAR-YOSEF, S.; LIVNAT, J. Auditor selection: an incentive signaling approach. Accounting and Business Research, v. I4, n. 56, p. 30I-309, I984.

BAUER, R. et al. Empirical evidence on corporate governance in Europe: the effect on stock returns, firm value and performance. Working Paper. EFMA 2004 Basel Meetings Paper. 2003. Disponível em: <http://ssrn.com/abstract=444543>. Acesso em: 3I jul. 2008.

BEAVER, W. H. Financial reporting. The Accounting Revolution, New Jersey, v. 3, n. 3, p. 243-252, I98I. BEAVER, W. H. Perspectives on recent capital market research. The Accounting Review, v. 2, p. 453-474, 2002.

BHAT, G. et al. Does corporate governance transparency affect the accuracy of analyst forecast? Accounting and Finance, v. 46, p. 715-732, 2006.

BHATTACHARYA, S. Imperfect information, dividend policy and the "bird in the hand" fallacy. Bell Journal of Economics, v. Io, n. I, p. 259-270, I979.

BHOJRAJ, S.; SENGUPTA, P. Effect of corporate governance on bond ratings and yields: the role of institutional investors and outside directors. Journal of Business, v. 76, p. 455-475, 2003.

BISHOP, W. "Is he married?" Marriage as information. University of Toronto Law Journal, v. 34, p. $245-263,1984$.

BLACK, B. The corporate governance behavior and market value of Russian firms. Emerging Markets Review, v. 2, p. 89-108, 200I. Disponível em: <http://ssrn.com/abstract=2630I4>. Acesso em: 25 jan. 2008. 
BLACK, B. et al. Does corporate governance predict firm's market values? Evidence from Korea. The Journal of Law, Economics, and Organization, v. 22, n. 2, p. 366-413, 2006.

BM\&FBOVESPA. Bolsa de valores de São Paulo. 2008. Disponível em: <http://www.bmfbovespa. com.br>. Acesso em: 25 jan. 2008.

BRAINARD, S. L.; MARTIMORT, D. Strategic trade policy design with asymmetric information and public contracts. Review of Economic Studies, v. 63, p. 8I-I05, I996.

BROWN, L. Analysts forecast errors and their implications for security analysis: an alternative perspective. Financial Analysts Journal, v. 52, n. I, p. 40-47, I996.

BROWN, L. Analyst forecasting errors: additional evidence. Financial Analysts Journal, v. 53, p. 8I-88, I997.

BROWN, L. Managerial behavior and the bias in analysts' earnings forecasts. Working Paper. Georgia State University, I998. Disponível em: <http://ssrn.com/abstract=II3508>. Acesso em: 4 set. 2008.

BROWN, L. D.; CAYLOR, M. L. Corporate governance and firm performance. Working Paper. 2004. Disponível em: <http://ssrn.com/abstract=586423>. Acesso em: 3I jul. 2008.

BUSHMAN, R. M.; SMITH, A. Financial accounting information and corporate governance. Journal of Accounting and Economics, v. 32, p. 237-333, 2001.

BUSHMAN, R. M.; SMITH, A. J. Transparency, financial, accounting information and corporate governance. Federal Reserve Bank of New York Economic Policy Review, v. 9, n. I, p. 65-87, 2003.

BUSHMAN, R. M. et al. Financial accounting information, organizational complexity and corporate governance systems. Journal of Accounting and Economics, v. 37, p. I67-201, 2004.

BYARD, D.; LI, Y.; WEINTROP, J. Corporate governance and the quality of financial analysts' information. Journal of Accounting and Economics, n. 25, p. 609-625, 2006.

CHIANG, H.; CHIA, F. Analyst's financial forecast accuracy and corporate transparency. Proceedings of the Academy of Accounting and Financial Studies, Memphis, v. IO, n. I, p. 9-I4, 2005.

CLEMENT, M. Analyst forecast accuracy: do ability, resources, and portfolio complexity matter? Journal of Accounting and Economics, v. 27, p. 285-303, I999.

COLLIE, D. R.; HVIID, M. International procurement as a signal of export quality. Economic Journal, v. III, n. 470, p. 374-90, 200 I.

CONROY, R.; HARRIS, R. Consensus forecasts of corporate earnings: analysts' forecasts and time series methods, Management Science, v. 33, n. 6, p. 725-738, I987.

DECHOW, P.; HUTTON, A.; SLOAN, R. The relation between analysts' forecast of long-term earnings growth and stock price performance following equity offerings. Contemporary Accounting Research, v. I7, n. I, p. I-32, 2000.

DECHOW, P. M.; SCHRAND, C. M. Earnings quality. The Research Foundation of CFA Institute, v. 2004, n. 3, I5I p., 2004 .

DURNEV, A.; KIM, H. To steal or not to steal: firm attributes, legal environment, and valuation. In: ANNUAL CONFERENCE ON FINANCIAL ECONOMICS AND ACCOUNTING (FEA), I4., AFA, 2004, San Diego. Anais... San Diego, 2004.

DURU, A.; REEB, D. International diversification and analysts' forecast accuracy and bias. The Accounting Review, v. 77, n. 2, p. 415-433, 2002.

FARBER, D. A. Rights as signals. Journal of Legal Studies, v. 3I, n. I, p. 83-98, 2002. 
FARBER, D. B. Restoring trust after fraud: does corporate governance matter? The Accounting Review, v. 80, p. 539-56I, 2005.

FÁVERO, L. P. L. et al. Análise de dados - modelagem multivariada para tomada de decisões. Rio de Janeiro: Elsevier, 2009.

FRANCO, D. Projeções de lucros sistematicamente exageradas: um estudo para o Brasil. Revista Brasileira de Economia, Rio de Janeiro, v. 56, n. 4, p. 59I-603, 2002.

GILLAN, S. L. Recent developments in corporate governance: an overview. Journal of Corporate Finance, v. I2, p. 38I-402, 2006.

GLAZER, A.; KONRAD, K. A signaling explanation for private charity. American Economic Review, v. 86, n. 4, p. IOI9-I028, I996.

GOMPERS, P. A.; ISHII, J. L.; METRICK, A. Corporate governance and equity prices. Quarterly Journal of Economics, v. II8, n. I, p. IO7-I55, 2003.

GU, Z.; WU, J. Earnings skewness and analyst forecast bias. Journal of Accounting and Economics, v. 35, p. 5-29, 2003 .

HARRIS, M.; RAVIV, A. The theory of capital structure. The Journal of Finance, v. 46, n. I, p. 297-355, I99I.

HEALY, P.; PALEPU, K. G. Information asymmetry, corporate disclosure, and the capital markets: a review of the empirical disclosure literature. Journal of Accounting and Economics, v. 3I, p. 405-440, 200 I.

INSTITUTO BRASILEIRO DE GOVERNANÇA CORPORATIVA. Governança no Brasil. 2009. Disponível em: <http://www.ibgc.org.br>. Acesso em: I3 set. 2009.

JENSEN, M. C.; MECKLING, W. H. Theory of the firm: managerial behavior, agency costs and ownership structure. Journal of Financial Economics, v. 3, p. 305-360, 1976.

JOHN, K.; WILLIAMS, J. Dividends, dilution and taxes: a signaling equilibrium. Journal of Finance, v. 40, n. 4, p. 1053-1070, I985.

KIRMANI, A.; RAO, A. No pain, no gain: a critical review of the literature on signaling unobservable product quality. Journal of Marketing, v. 64, p. 66-79, 2000.

KLAPPER; L.; LOVE, I. Corporate governance, investor protection, and performance in emerging markets. Working Paper. World Bank Policy Research, n. 28I8, 2002. Disponível em: <http://ssrn. com/abstract=303979>. Acesso em: 25 jan. 2008.

KLEIN, L. S.; O'BRIEN, T. J.; PETERS, S. R. Debt vs. equity and asymmetric information: a review. The Financial Review, v. 37, n. 3, p. 317-349, 2002.

KOTHARI, S. P. Capital market research in accounting. Journal of Accounting and Economics, v. 3I, p. IO5-23I, 2001.

KREPS, D. M. Microeconomics for managers. New York: W. W. Norton \& Company, 2004.

LA PORTA, R.; LÓPEZ-DE-SILANES, F.; SHLEIFER, A. Corporate ownership around the world. Journal of Finance, v. 54, n. 2, p. 47I-517, I999.

LA PORTA, R.; LÓPEZ-DE-SILANES, F.; SHLEIFER, A.; VISHNY, R. Law and finance. Journal of Political Economy, v. IO6, p. III3-II55, I998.

LA PORTA, R. et al. Investor protection and corporate valuation. The Journal of Finance, v. 57, n. 3, p. II47-II7O, 2002.

LANG, M. H.; LUNDHOLM, R. J. Corporate disclosure policy and analyst behavior. The Accounting Review, v. 7I, n. 4, p. 467-492, I996. 
LAPAN, H. E.; SANDLER, T. Terrorism and signaling. European Journal of Political Economy, v. 9, n. 3, p. 383-397, I993.

LARCKER, D.; RICHARDSON, S. A.; TUNA, I. A. Corporate governance, accounting outcomes, and organizational performance. The Accounting Review, v. 82, n. 4, p. 963-1008, 2007.

LEAL, R. do P. C.; CARVALHAL-DA-SILVA, A. L. Corporate governance and value in Brazil (and Chile). Research Network Working Paper, Coppead Graduate School of Business at the Federal University of Rio de Janeiro, n. R-5I4, 2005.

LELAND, H. E.; PYLE, D. H. Information asymmetries, financial structure, and financial intermediation. The Journal of Finance, v. 32, n. 2, p. 37I-387, I977.

LIM, T. Are analysts' forecasts optimistically biased? Working Paper. Darmouth University, I998. LOPES, A. B. A relevância da informação contábil para o mercado de capitais: o modelo de Ohlson aplicado à Bovespa. 200I. Tese (Doutorado em Controladoria e Contabilidade)-Faculdade de Economia, Administração e Contabilidade, Universidade de São Paulo, São Paulo, 200 I.

LOPES, A. B. The relation between firm-specific corporate governance, cross-listing and the informativeness of accounting numbers in Brazil. 2008. Thesis (Doctor of Philosophy Degree in the Faculty of Humanities)-University of Manchester, Manchester, 2008.

LOPES, A. B.; MARTINS, E. Teoria da contabilidade: uma nova abordagem. São Paulo: Atlas, 2007. LOPES, A. B.; WALKER, M. Firm-level incentives and the informativeness of accounting reports: an experiment in Brazil. Working Paper. 2008. Disponível em: <http://ssrn.com/abstract=I09578I>. Acesso em: 25 mar. 2008.

MARTINEZ, A. L. Analisando os analistas: estudo empírico das projeções de lucros e das recomendações dos analistas de mercado de capitais para as empresas brasileiras de capital aberto. 2004 . Tese (Doutorado em Administração de Empresas)-Fundação Getulio Vargas, São Paulo, 2004.

MARTINEZ, A. L.; SALIM, J. J. Analisando as previsões de resultados contábeis dos analistas de empresas brasileiras. In: ENCONTRO DA ANPAD, 28., 2004. Anais... Curitiba: Anpad, 2004. I CD-ROM.

MILGRON, P.; ROBERTS, J. Economics, organization and management. New Jersey: Prentice Hall, I992.

MILLER, M. H.; ROCK, K. Dividend policy under asymmetric information. The Journal of Finance, v. 40, n. 4, p. IO3I-IO5I, I985.

MORRIS, R. D. Signalling, agency theory and accounting policy choice. Accounting and Business Research, v. I8, n. 69, p. 47-69, 1987.

MYERS, S. C.; MAIJLUF, N. S. Corporate financing and investment decisions. When firms have information that investors do not have. Journal of Financial Economics, v. I3, n. 2, p. I87-221, I984. PINDYCK, R.; RUBINFELD, D. L. Microeconomia. 5. ed. São Paulo: Prentice Hall, 2002.

RICHARDSON, S. A.; TEOH, S. S. H.; WYSOCKI, P. D. Tracking analysts' forecasts over the annual earnings horizon: are analysts' forecasts optimistic or pessimistic? Working Paper. University of Michigan, I999. Disponível em: <http://ssrn.com/abstract=I68I9I>. Acesso em: I3 ago. 2008.

ROSS, S. A. The determination of financial structure: the incentive-signaling approach. Bell Journal of Economics, v. 8, n. I, p. 23-40, I977.

ROWTHORN, R. Marriage as signal. In: ROWTHORN, R.; DNES, A. The law and economics of marriage and divorce. Cambridge: Cambridge University Press, 2002. p. I79-2II. 
SARLO NETO, A. Relação entre a estrutura de propriedade e a informatividade dos lucros contábeis no mercado brasileiro. 2009. Tese (Doutorado em Controladoria e Contabilidade)-Faculdade de Economia, Administração e Contabilidade, Universidade de São Paulo, São Paulo, 2009.

SCHIPPER, K. Commentary on analysts' forecast. Accounting Horizons, v. 3, p. I05-I2I, I99I.

SHLEIFER, A.; VISHNY, R. A survey on corporate governance. The Journal of Finance, v. 52, n. 2, p. 737-783, I997.

SHY, O. Exporting as a signal for product quality. Economica, v. 67, p. 79-90, 2000.

SILVA, H. R. L. F. da. A capacidade previsionária no mercado acionário brasileiro: um estudo focado nas previsões dos analistas de investimentos. In: ENCONTRO DA ANPAD, 22., I998, Foz do Iguaçu. Anais... Foz do Iguaçu: Anpad, I998. I CD-ROM.

SILVEIRA, A. D. M. Governança corporativa e a estrutura de propriedade: determinantes e relação com o desempenho das empresas no Brasil. Tese (Doutorado em Administração)-Faculdade de Economia, Administração e Contabilidade da Universidade de São Paulo, 2004.

SLOAN, R. G. Financial accounting information and corporate governance: a discussion. Journal of Accounting and Economics, v. 32, p. 335-347, 200I.

SPENCE, A. M. Job market signaling. The Quarterly Journal of Economics, v. 83, n. 3, p. 355-374, I973. TERRA, P. R. S.; LIMA, J. B. N. de. Governança corporativa e a relação do mercado de capitais à divulgação das informações contábeis. Revista Contabilidade \& Finanças, São Paulo, n. 42, p. 35-49, 2006. TREBILCOCK, M. J. Marriage as a signal. In: BUCKLEY, F. H. The fall and rise of freedom of contract. Durham: Duke University Press, I999. p. 245-255.

VARIAN, H. R. Microeconomia. 6. ed. Rio de Janeiro: Elsevier, 2003.

WOOLDRIDGE, J. M. Introdução à econometria: uma abordagem moderna. São Paulo: Pioneira Thomson Learning, 2006.

YU, F. Essays on governance and earnings management. 2005. Dissertation (Degree of Doctor of Philosophy)-University of Chicago, Chicago, 2005. 